\title{
Impact of splenomegaly and splenectomy on prognosis in hepatocellular carcinoma with portal vein tumor thrombus treated with hepatectomy
}

\author{
Zong-Tao Chai ${ }^{1 \#}$, Xiu-Ping Zhang ${ }^{2 \#}$, Min Shao ${ }^{3 \#}$, Jian-Yang Ao ${ }^{4 \#}$, Zhen-Hua Chen ${ }^{1 *}$, Fan Zhang ${ }^{5}$, \\ Yi-Ren $\mathrm{Hu}^{6}$, Cheng-Qian Zhong ${ }^{7}$, Jian-Hua Lin ${ }^{8}$, Kun-Peng Fang ${ }^{9}$, Meng-Chao Wu ${ }^{1}$, Wan Yee Lau ${ }^{1,10}$, \\ Shu-Qun Cheng ${ }^{1}$
}

${ }^{1}$ Department of Hepatic Surgery VI, Eastern Hepatobiliary Surgery Hospital, Second Military Medical University, Shanghai, China; ${ }^{2}$ Department of Hepatobiliary and Pancreatic Surgical Oncology, The First Medical Center of Chinese People's Liberation Army (PLA) General Hospital, Beijing, China; ${ }^{3}$ Shanghai Institutes for Biological Sciences, Chinese Academy of Sciences, Shanghai, China; ${ }^{4}$ Department of Biliary Surgery I, Eastern Hepatobiliary Surgery Hospital, Second Military Medical University, Shanghai, China; ${ }^{5}$ Department of Hepatobiliary Surgery, Affiliated Hospital of Binzhou Medical College, Yantai, China; ${ }^{6}$ Department of General Surgery, Wenzhou People's Hospital, Wenzhou, China; ${ }^{7}$ Longyan First Hospital, Affiliated to Fujian Medical University, LongYan, China; ${ }^{8}$ Second Affiliated Hospital of Wenzhou Medical University, Wenzhou, China; ${ }^{9}$ Qingdao Sixth People's Hospital, Qingdao, China; ${ }^{10}$ Faculty of Medicine, The Chinese University of Hong Kong, Hong Kong, China

Contributions: (I) Conception and design: SQ Cheng, WY Lau, ZT Chai, XP Zhang, ZH Chen, JY Ao; (II) Administrative support: SQ Cheng; (III) Provision of study materials or patients: F Zhang, YR Hu, CQ Zhong, JH Lin, KP Fang, H Chen; (IV) Collection and assembly of data: XP Zhang, ZH Chen; (V) Data analysis and interpretation: ZT Chai, XP Zhang, M Shao; (VI) Manuscript writing: All authors; (VII) Final approval of manuscript: All authors.

\#These authors contributed equally to this work.

Correspondence to: Shu-Qun Cheng, MD, PhD. Eastern Hepatobiliary Surgery Hospital, Second Military Medical University, 225 Changhai Road, Shanghai 200433, China. Email: chengshuqun@aliyun.com.

Background: Hepatocellular carcinoma (HCC) commonly occurs in patients with splenomegaly. This study aimed to investigate the impact of splenomegaly with or without splenectomy on long-term survival of HCC patients with portal vein tumor thrombus (PVTT) treated with liver resection (LR).

Methods: HCC patients with PVTT who underwent LR from 2005 to 2012 from 6 hospitals were retrospectively studied. The long-term overall survival (OS) and recurrence-free survival (RFS) were compared between patients with or without splenomegaly, and between patients who did or did not undergo splenectomy for splenomegaly. Propensity score matching (PSM) analysis was performed to match patients in a $1: 1$ ratio.

Results: Of 716 HCC patients with PVTT who underwent LR, 140 patients had splenomegaly (SM group) and 576 patients had no splenomegaly (non-SM group). The SM group was further subdivided into 49 patients who underwent splenectomy (SPT group), and 91 patients who did not received splenectomy (nonSPT group). PSM matched 140 patients in the SM group, and 49 patients in the SPT group. Splenomegaly was an independent risk factor of poor RFS and OS. The OS and RFS rates were significantly better for patients in the non-SM group than the $\mathrm{SM}$ group (OS: $\mathrm{P}<0.001$; RFS: $\mathrm{P}<0.001$ ), and for patients in the SPT group than the non-SPT group (OS: $\mathrm{P}<0.001$; RFS: $\mathrm{P}<0.001)$.

Conclusions: Patients who had splenomegaly had significantly worse survival in HCC patients with PVTT. Splenectomy for splenomegaly significantly improved long-term survival in these patients.

Keywords: Hepatocellular carcinoma (HCC); portal vein tumor thrombus (PVTT); splenomegaly; splenectomy

Submitted Mar 06, 2020. Accepted for publication Oct 16, 2020.

doi: $10.21037 /$ atm-20-2229

View this article at: http://dx.doi.org/10.21037/atm-20-2229 


\section{Introduction}

Worldwide, hepatocellular carcinoma (HCC) is one of the most common cancers and the third leading cause of cancer-related death (1). In excess of $80 \%$ of HCC occur in Africa and Asia due to the prevalence of hepatitis $B$ virus (HBV) infection in these regions. Portal vein tumor thrombus (PVTT) occurs in $44 \%$ to $62 \%$ of HCC patients and, without treatment, the median survival time (MST) is dismal, ranging from 2.7 to 4.0 months $(2,3)$. Because PVTT complicating HCC often indicates more aggressive disease, reduced liver function, and elevated recurrence rates following treatment, it is considered a strong negative prognostic risk factor.

The best treatment strategy for HCC patients with PVTT remains controversial. HCC with PVTT is considered an advanced stage disease by the Barcelona Clinic Liver Cancer (BCLC) Staging System, and the American Association for the Study of Liver Diseases (AASLD). In most HCC staging classifications, sorafenib is considered the standard of care $(4,5)$. However, the MST of HCC patients with advanced stage disease treated with sorafenib is only approximately 6.5 months (6-8). Recently, increasing evidence has shown R0 liver resection (LR) can yield better survival compared to nonoperative treatments, especially for patients whose PVTT involves first or second order portal vein branches $(2,3,9)$.

Patients with HCC commonly have portal hypertension and splenomegaly with associated hypersplenism (defined as pathologic spleen) (10). A pathologic spleen in a patient with HCC was once considered a contraindication to hepatectomy (11-13) due to increased surgical risks and poor long-term survival. Splenectomy for patients with pathologic spleen is recommended by the AASLD (14) as it can improve liver fibrosis, restore immune function, improve low platelet and white blood cell counts and reduce portal venous pressure $(10,15,16)$. Synchronous splenectomy and hepatectomy has been reported to improve survival in patients with HCC and cirrhotic hypersplenism (17-19). Because a high splenic volume (a measure of splenomegaly/ pathologic spleen) is a predictor of poor survival in HCC patients, Takeishi et al. found that combined splenectomy and hepatectomy in such patients should be the appropriate treatment (20). Similarly, the PVTT in HCC patients may obstruct blood flow through the portal venous system, inducing portal hypertension and pathologic spleen, with consequent negative impact on survival. However, the specific influence of pathologic spleen in HCC patients with
PVTT and the impact of splenectomy remain unclear.

The aim of this study was to investigate the long-term survival of surgically treated patients with HCC and PVTT, and to compare long-term survival when treated either with or without splenectomy in the subset of these patients having a pathologic spleen.

We present the following article in accordance with the STROBE reporting checklist (available at http://dx.doi. org/10.21037/atm-20-2229).

\section{Methods}

\section{Patients}

The study comprised 716 consecutively accrued HCC patients with PVTT, who underwent LR from 2005 to 2012 in 6 hospitals. Clinicopathologic, demographic, and pathology data were recorded. The study was conducted in accordance with the Declaration of Helsinki (as revised in 2013). The study was approved by the Institutional Ethics Committees of the Eastern Hepatobiliary Surgery Hospital. (NO.: EHBHKY-2015-01-028) and informed consent was taken from all the patients.

The diagnostic criteria to verify PVTT included both imaging examinations [ultrasound, computed tomography (CT) and magnetic resonance imaging (MRI)], and intraoperative and postoperative histopathology. Based on the classification proposed by Cheng to describe the specific site of portal vein involvement (21), the categories are I, segmental/sectoral branches of the portal vein; II, left or right portal vein; III, main portal vein (MPV); and IV, thrombus in MPV extending to involve the superior mesenteric vein.

\section{Inclusion and exclusion criteria}

The inclusion criteria were (I) resectable HCC; (II) verification of PVTT; (III) patients with PVTT that was limited to Cheng type I and II PVTT; (IV) absence of macroscopic hepatic vein tumor thrombus, macroscopic bile duct tumor, local extrahepatic spread or distant metastases; (V) no other associated malignancies. Exclusion criteria included (I) liver function of Child-Pugh class C; (II) operative contraindications to splenectomy; or (III) incomplete data. HCC patients with PVTT were divided into two groups according to whether they had splenomegaly. Those patients who had splenomegaly were further subdivided into two subgroups according to whether they had undergone splenectomy prior to hepatectomy. 


\section{Diagnosis of splenomegaly and the criteria of splenectomy}

Splenomegaly was diagnosed by physical examination and imaging studies. Splenomegaly with hypersplenism was defined as a pathological spleen. Patients underwent splenectomy on the basis of the following criteria: splenomegaly with hypersplenism classified as greater than class I (spleen enlarged beyond left subcostal margin and palpable); hypersplenism with a concurrent white blood cell count (WBC) count of less than $3.0 \times 10^{9} / \mathrm{L}$ and PLT count less than $80 \times 10^{9} / \mathrm{L}(18)$; or splenomegaly of grade 1 or greater with a WBC count of less than $2.0 \times 10^{9} / \mathrm{L}$ or a PLT count below $50 \times 10^{9} / \mathrm{L}(22)$.

\section{Follow-up}

All patients were followed every 2 to 3 months until death or if they drop out of the follow-up program. Specifically included was the thickness of the splenic hilum (which reflects the extent of splenomegaly) as defined by CT or MRI, measured in the central part of the hilum, perpendicular to the long axis of the spleen (23). When tumor recurrence was diagnosed, patients were treated with percutaneous ethanol injection, radiofrequency ablation, transhepatic arterial chem therapy and embolization, or LR, depending on the general condition of the patient, the functional liver reserve, and the pattern of tumor recurrence.

\section{Statistical analysis}

Continuous data was reported as medians with interquartile range (IQR) and were compared using the Mann-Whitney test. Normally distributed variables was reported as mean and standard deviation and were compared using the Student's t test. Categorical variables was presented as numbers or frequencies (\%), and were compared using the Chi-square test or the Fisher's exact test. Survival curves were generated using the Kaplan-Meier method and compared with the log-rank test. Univariate and multivariate analyses were analyzed using the Cox proportional hazards stepwise model. Factors with statistical significance on univariate analysis were incorporated into multivariate analysis. Propensity score matching (PSM) was used in this study as there was heterogeneity in the study populations between the splenomegaly group (SM) and the non-splenomegaly group (non-SM) and between the splenectomy group (SPT) and the non- splenectomy group (non-SPT). Patients in the SM and non-SM groups were matched to the non-SM group using a matching ratio of $1: 1$, with the closest estimated propensity score (PS) within 0.1 of the standard deviation of the logit of PS. Patients in the SPT and non-SPT groups were similarly matched. A $\mathrm{P}$ value $<0.05$ was considered statistically significant. Following completion of PSM, univariate, multivariate logistic regression and Kaplan-Meier analyses were performed. The data analyses were performed using the SPSS software version 22.0 (Chicago IL, USA).

\section{Results}

\section{Patient characteristics}

The flowchart in Figure 1 shows the selection details of the 716 HCC patients with PVTT enrolled in this study. The baseline characteristics of the patients in the SM and non-SM groups are shown in Table 1, and the patients in the SPT and non-SPT groups are shown in Table 2. After PSM, these clinicopathological features were well-balanced (Tables S1,S2).

\section{Risk factors of poor recurrence-free survival (RFS) and overall survival (OS) for patients in the SM and non-SM groups}

Univariate and multivariate analyses before PSM demonstrated that incomplete tumor encapsulation $(\mathrm{P}<0.001)$, aspartate aminotransferase level (AST, $\mathrm{P}<0.001$ ), and thickness of splenic hilum $(\mathrm{P}=0.006)$ were independent risk factors of poor RFS (Table 3). Furthermore, $\alpha$-fetoprotein level $(\mathrm{P}<0.001)$, carcinoembryonic antigen level (CEA, $\mathrm{P}<0.001)$ incomplete tumor encapsulation $(\mathrm{P}<0.001)$ and thickness of splenic hilum $(\mathrm{P}=0.004)$ were independent risk factors of poor OS (Table 4). In contrast, sex, age, HBV infection, hepatitis $\mathrm{C}$ virus infection, gastroesophageal varices, cirrhosis, histopathological grading, carcinoembryonic antigen (CEA), carbohydrate Atigen 19-9 (CA199), prothrombin time (PT), $\alpha$-fetoprotein (AFP), alanine aminotransferase (ALT), total bilirubin (TBIL), albumin (ALB), tumor diameter, number of tumors, PVTT, and BCLC staging were not significant factors influencing RFS or OS.

\section{Survival Analysis of patients in the SM and non-SM groups}

Before PSM, the median RFS (MRFS 95\% CI) was 6.5 (6.37.8) months for the non-SM group, and 4.3 (3.8-5.3) months 


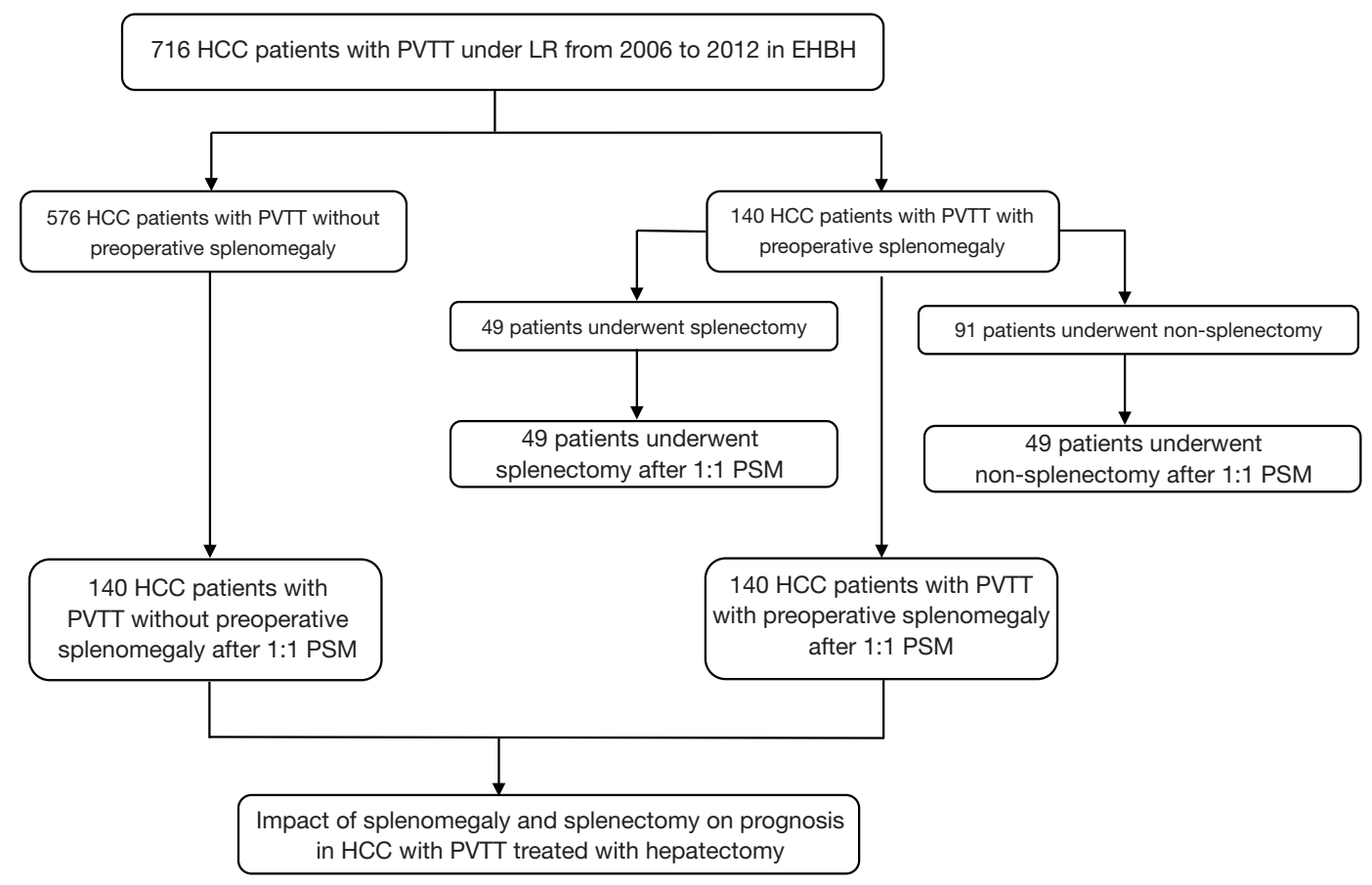

Figure 1 Flow chart for the selection of HCC patients enrolled in this study. HCC, hepatocellular carcinoma.

Table 1 The clinicopathological features of patients with or without splenomegaly before PSM

\begin{tabular}{|c|c|c|c|}
\hline Clinical variables & Splenomegaly $(n=140)$ & Non-splenomegaly $(n=576)$ & $P$ \\
\hline Sex & & & 0.948 \\
\hline Male & $126(90.0 \%)$ & $522(90.6 \%)$ & \\
\hline Female & $14(10.0 \%)$ & $54(9.4 \%)$ & \\
\hline No & $33(23.6 \%)$ & $164(28.5)$ & \\
\hline Yes & $107(76.4 \%)$ & $412(71.5 \%)$ & \\
\hline $\mathrm{HBsAg}$ & & & 0.912 \\
\hline No & $14(10 \%)$ & $62(10.8 \%)$ & \\
\hline No\# of tumor & & & 0.940 \\
\hline Single & $122(87.1 \%)$ & $498(86.5 \%)$ & \\
\hline Multiple & $18(12.9 \%)$ & $78(13.5 \%)$ & \\
\hline PVTT & & & 0.963 \\
\hline I & $46(32.9 \%)$ & 193 (33.5\%) & \\
\hline II & $94(67.1 \%)$ & $383(66.5 \%)$ & \\
\hline
\end{tabular}

Table 1 (continued) 
Table 1 (continued)

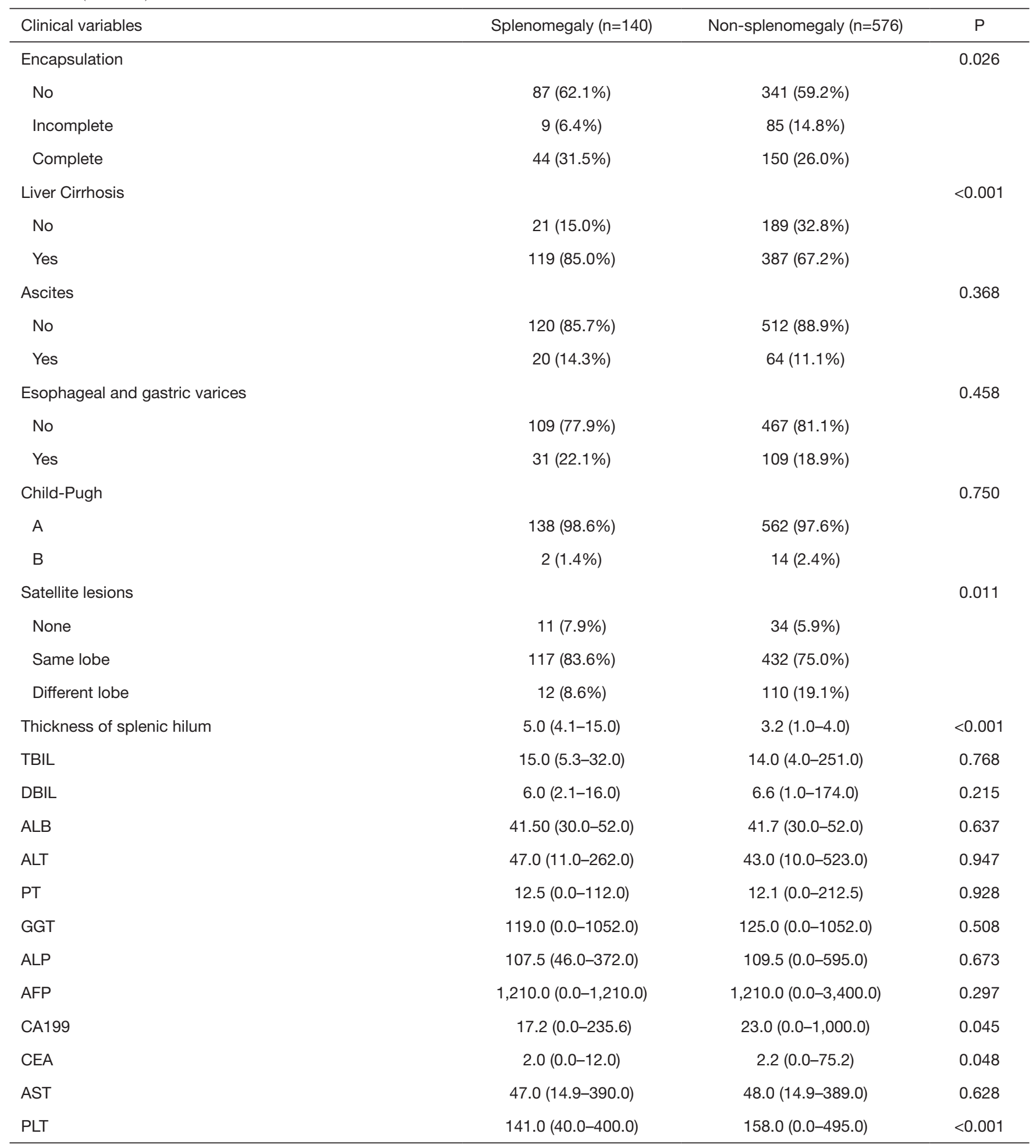

Data were presented as $\mathrm{n}(\%)$ or medians with interquartile range (IQR). PSM, propensity score matching; HBsAg, Hepatitis B surface antigen; PVTT, portal vein tumor thrombus; TBIL, Total Bilirubin; DBIL, Direct Bilirubin; ALB, Albumin; ALT, Alanine Aminotransferase; PT, Prothrombin time; GGT, $\gamma$-Glutamyltransferase; ALP, Alkaline phosphatase; AFP, $\alpha$-fetoprotein; CA199, Carbohydrate Atigen 19-9; CEA, Carcinoembryonic antigen; AST, Aspartate Aminotransferase; PLT, Platelet. 
Table 2 The clinicopathological features of patients with or without splenectomy before PSM

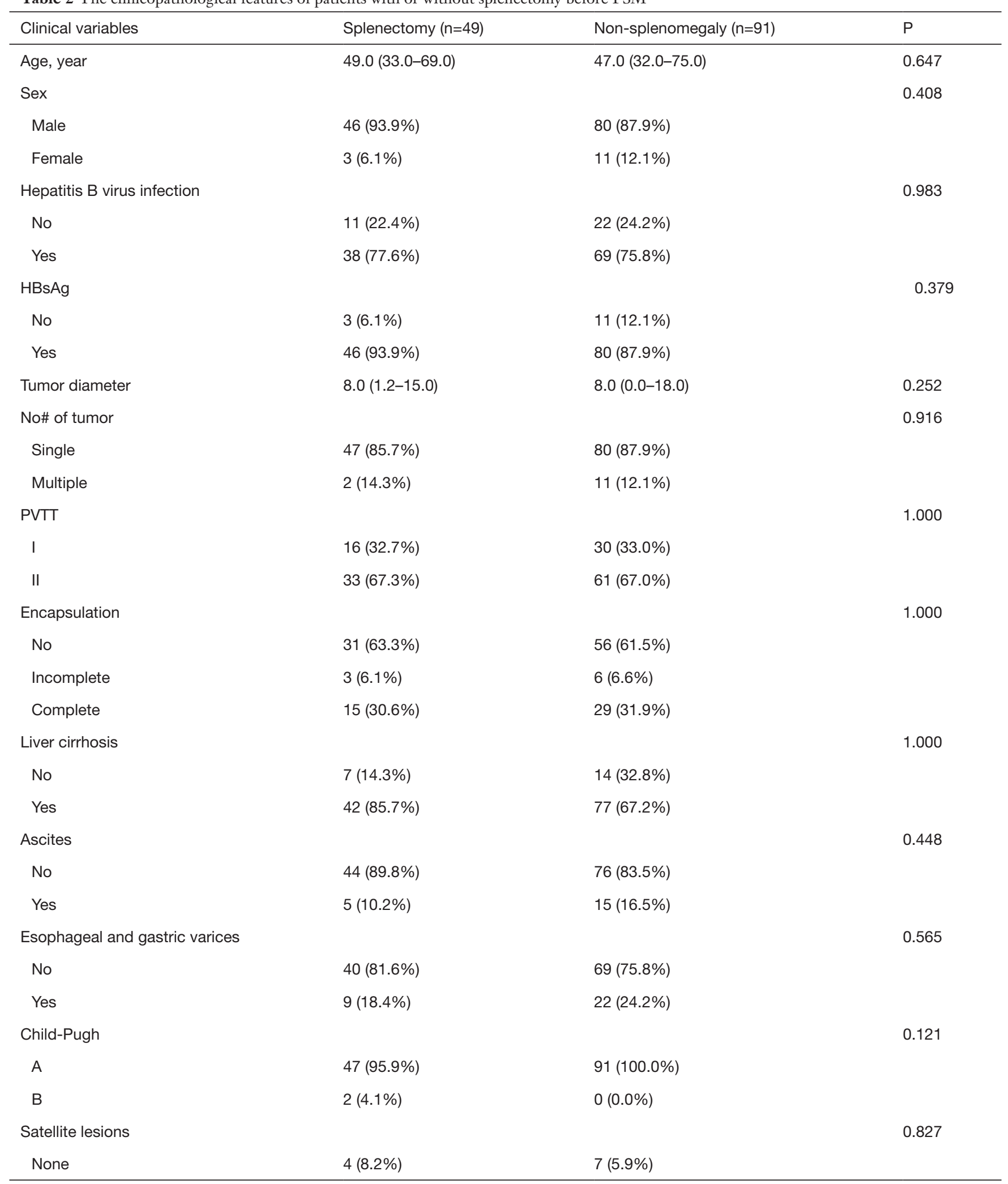

Table 2 (continued) 
Table 2 (continued)

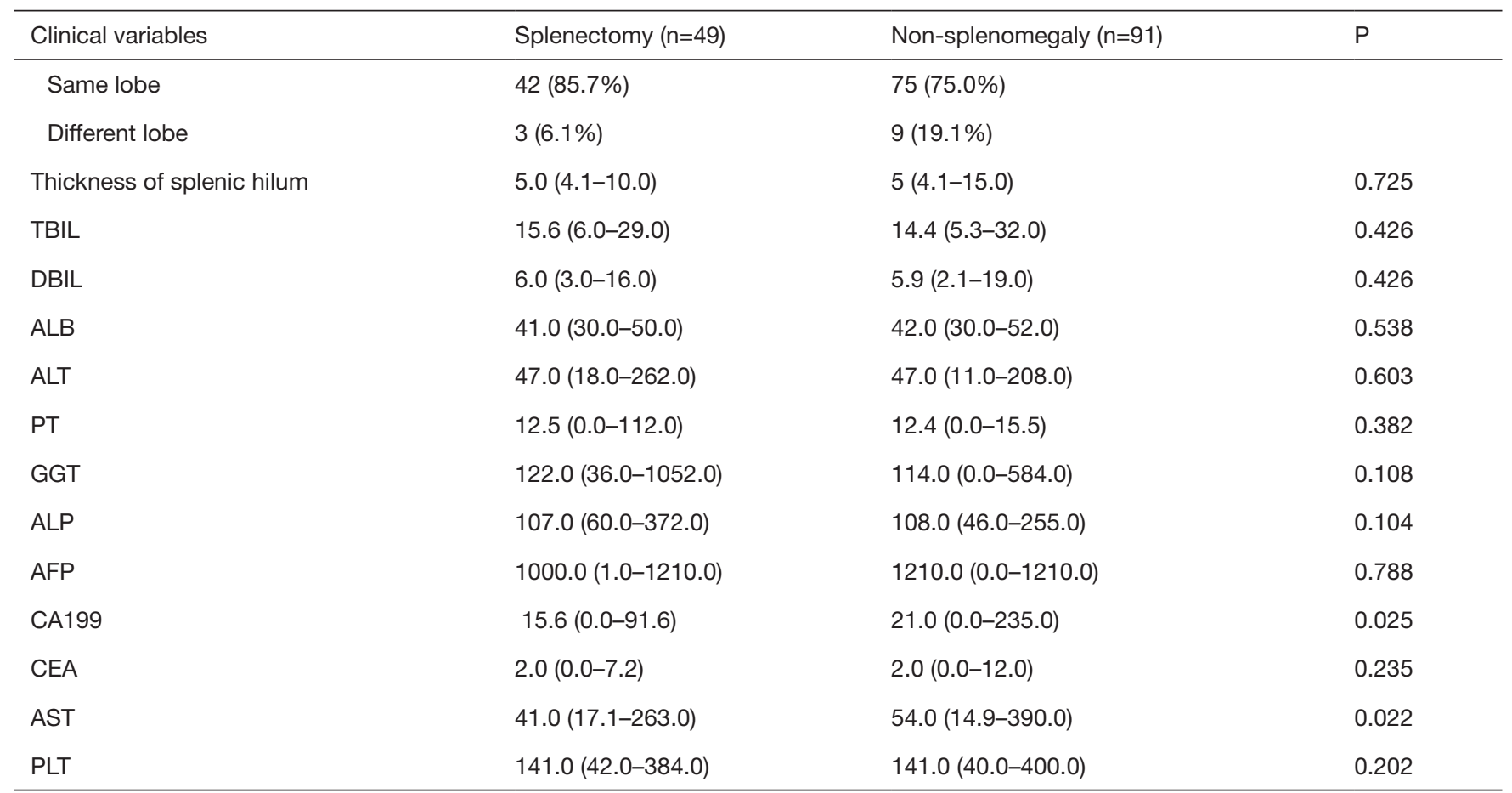

Data were presented as $\mathrm{n}(\%)$ or medians with interquartile range (IQR). PSM, propensity score matching; HBsAg, Hepatitis $B$ surface antigen; PVTT, portal vein tumor thrombus; TBIL, Total Bilirubin; DBIL, Direct Bilirubin; ALB, Albumin; ALT, Alanine Aminotransferase; PT, Prothrombin time; GGT, $\gamma$-Glutamyltransferase; ALP, Alkaline phosphatase; AFP, $\alpha$-fetoprotein; CA199, Carbohydrate Atigen 19-9; CEA, Carcinoembryonic antigen; AST, Aspartate Aminotransferase; PLT, Platelet.

for the SM group (Table S3). The RFS of patients in the non-SM group was significantly better than the SM group (1 year, $32.3 \%$ vs. $17.6 \%$; 2 years, $21.1 \%$ vs. $6.8 \%$; 3 years, $16.1 \%$ vs. $5.4 \% ; \mathrm{P}<0.001$, Figure $2 A$ ). The median OS (MOS 95\% CI) for patients in the SM compared to nonSM groups were $7.4(6.7-13.9)$ months vs. $12.4(11.7-13.5)$ months (Table S4). The OS in the non-SM group was significantly better than that of the SM group (1 year, $51.7 \%$ vs. $25.7 \%$; 2 years, $28.0 \%$ vs. $10.2 \%$; 3 years, $18.6 \%$ vs. $7.2 \% ; \mathrm{P}<0.001$, Figure $2 B)$.

After PSM, the MRFS (95\% CI) was 6.3 (5.4-7.3) months for the non-SM group and $4.3(3.8-5.3)$ months for the SM group (Table S5). The RFS in the non-SM group was significantly better than that of the SM group (1 year, $22.8 \%$ vs. $17.6 \% ; 2$ years, $18.3 \%$ vs. $6.8 \% ; 3$ years, $7.2 \%$ vs. 5.4\%; $\mathrm{P}<0.001$, Figure $2 C$ ). The MOS (95\% CI) was 12.4 (10.3-13.8) months for the non-SM group and 7.4 (6.79.6) months for the SM group (Table S6). The OS in the non-SM group was significantly better than that of the SM group (1 year, $51.4 \%$ vs. $25.7 \%$; 2 years, $21.4 \%$ vs. $10.2 \%$;
3 years, $10.1 \%$ vs. $7.2 \%$; $\mathrm{P}<0.001$, Figure $2 D)$.

\section{Survival analysis for patients in the SPT and non-SPT groups}

Before PSM, the MRFS (95\% CI) was $11.1(9.0-15.3)$ months for the non-SPT group and 3.5 (2.9-4.2) months for the SPT group (Table S5). The RFS in the SPT group was significantly better than that of the non-SPT group (1 year, $42.9 \%$ vs. $3.3 \%$; 2 years, $18.3 \%$ vs. $0 \%$; 3 years, $14.6 \%$ vs. $0 \%$; $\mathrm{P}<0.001$, Figure $3 A)$. The MOS (95\% CI) in the SPT vs. the non-SPT groups was $14.0(12.1-23.7)$ months vs. 6.2 (5.4-6.7) months (Table S5). The OS of patients in the SPT group was significantly better than that of the non-SPT group (1 year, $59.2 \%$ vs. $6.6 \% ; 2$ years, $38.9 \%$ vs. $0 \%$; 3 years, $13.2 \%$ vs. $0 \%$; $\mathrm{P}<0.001$, Figure $3 B$ ).

After PSM, the MRFS (95\% CI) was 11.1 (9.0-15.3) months for the SPT group and $3.6(2.7-4.6)$ months for the non-SPT group (Table S6). The RFS of patients in the SPT group was significantly better than that of the non- 
Table 3 Univariate and multivariable analysis for recurrence-free survival of patients with or without splenomegaly before PSM

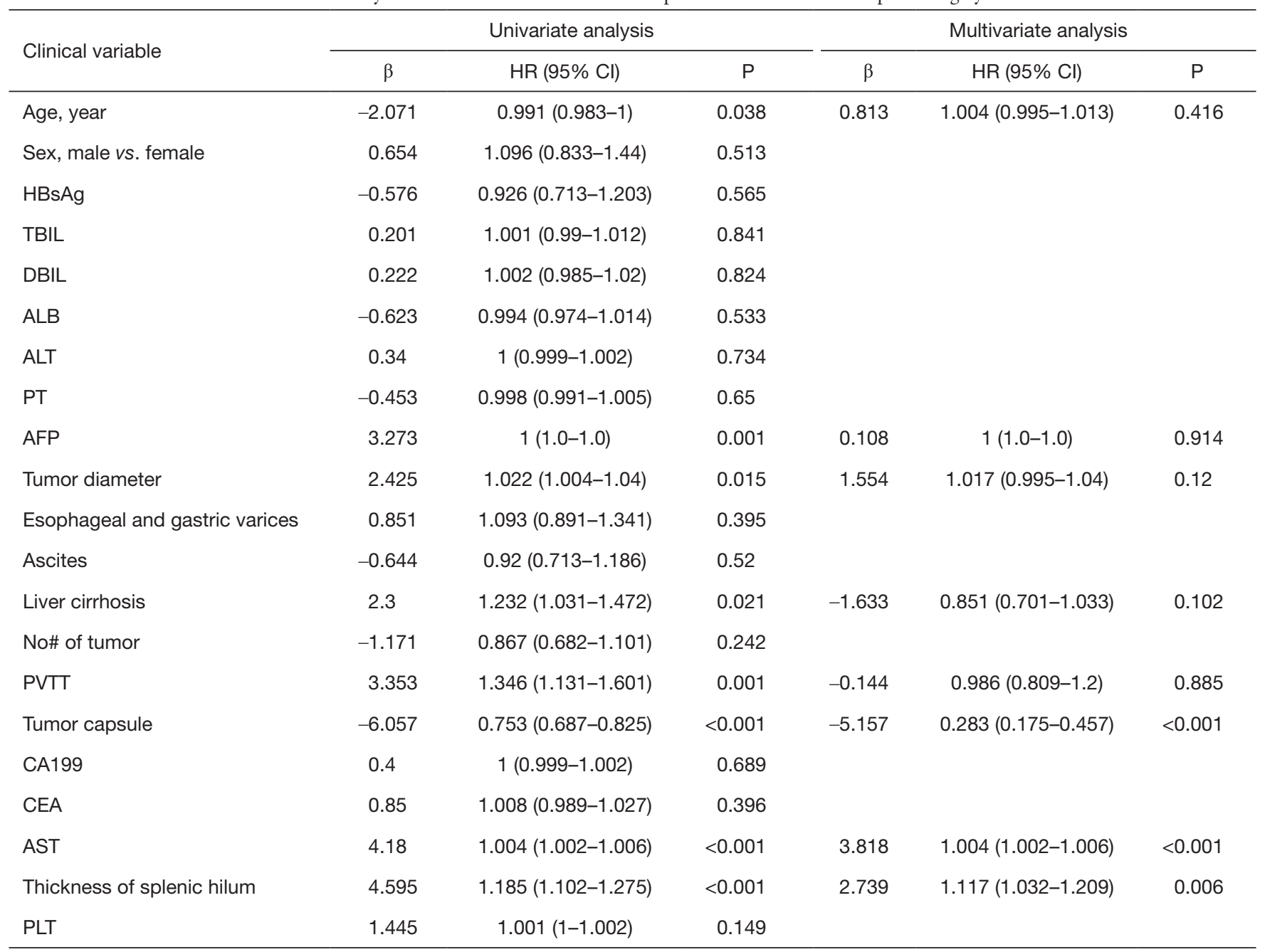

PSM, propensity score matching; HBsAg, Hepatitis B surface antigen; TBIL, Total Bilirubin; DBIL, Direct Bilirubin; ALB, Albumin; ALT, Alanine Aminotransferase; PT, Prothrombin time; AFP, $\alpha$-fetoprotein; PVTT, portal vein tumor thrombus; CA199, Carbohydrate Atigen 19-9; CEA, Carcinoembryonic antigen; AST, Aspartate Aminotransferase; PLT, Platelet.

SPT group (1 year, $42.9 \%$ vs. $2.0 \%$; 2 years, $18.3 \%$ vs. $0 \%$; 3 years, $14.6 \%$ vs. $0 \%$; $\mathrm{P}<0.001$, Figure $3 C$ ). The MOS was 14.0 (12.1-23.7) months for the SPT group and 6.3 (5.6-7.2) months for the non-SPT group (Table S6). The OS in the SPT group was significantly better than that of the nonSPT group (1 year, $59.2 \%$ vs. $4.1 \%$; 2 years, $38.9 \%$ vs. $0 \%$; 3 years, $13.2 \%$ vs. $0 \% ; \mathrm{P}<0.001$, Figure $3 D$ ).

\section{Discussion}

PVTT has been recognized as one of the most significant prognostic factors of poor survival in HCC patients $(2,24)$. While many therapeutic modalities have been used to treat these patients, their effectiveness remains unsatisfactory. However, advances in both surgical treatment and perioperative management have rendered feasible R0 LR for the complex combination of HCC with types I and II PVTT $(3,9,25)$. To our knowledge, there have been no prior studies that have assessed survival of HCC patients with PVTT and pathologic spleen, comparing treatment with or without splenectomy following LR.

Macrovascular invasion of the portal venous system presenting as PVTT is virtually always classified as advanced HCC $(26,27)$. However, the specific factors impacting survival of HCC patients with PVTT remain elusive. A recent study reported that $\mathrm{HBV}$ infection and activity of 
Table 4 Univariate and Multivariable Analysis for Overall Survival of Patients with or without Splenomegaly before PSM

\begin{tabular}{|c|c|c|c|c|c|c|}
\hline Clinical variable & \multicolumn{3}{|c|}{ Univariate analysis } & \multicolumn{3}{|c|}{ Multivariate analysis } \\
\hline Age, year & -1.648 & $0.993(0.985-1.001)$ & 0.099 & & & \\
\hline Sex, male vs. female & 0.137 & $1.019(0.776-1.34)$ & 0.891 & & & \\
\hline HBsAg & -1.269 & $0.844(0.65-1.097)$ & 0.204 & & & \\
\hline DBIL & -0.472 & $0.997(0.985-1.01)$ & 0.637 & & & \\
\hline ALB & -0.518 & $0.995(0.975-1.015)$ & 0.605 & & & \\
\hline ALT & -0.333 & $1(0.998-1.001)$ & 0.739 & & & \\
\hline PT & -0.838 & $0.997(0.99-1.004)$ & 0.402 & & & \\
\hline $\begin{array}{l}\text { Esophageal and gastric } \\
\text { varices }\end{array}$ & -0.092 & $0.99(0.807-1.215)$ & 0.927 & & & \\
\hline Ascites & -0.405 & $0.949(0.736-1.224)$ & 0.686 & & & \\
\hline Liver cirrhosis & 1.863 & $1.184(0.991-1.415)$ & 0.062 & & & \\
\hline No\# of tumor & -0.383 & $0.954(0.751-1.213)$ & 0.702 & & & \\
\hline PVTT & 1.233 & $1.116(0.938-1.327)$ & 0.218 & & & \\
\hline Tumor capsule & -6.288 & $0.739(0.673-0.812)$ & $<0.001$ & -4.253 & $0.809(0.734-0.892)$ & $<0.001$ \\
\hline CA199 & 1.013 & 1.001 (0.999-1.002) & 0.311 & & & \\
\hline
\end{tabular}

PSM, propensity score matching; HBsAg, Hepatitis B surface antigen; TBIL, Total Bilirubin; DBIL, Direct Bilirubin; ALB, Albumin; ALT, Alanine Aminotransferase; PT, Prothrombin time; AFP, $\alpha$-fetoprotein; PVTT, portal vein tumor thrombus; CA199, Carbohydrate Atigen 19-9; CEA, Carcinoembryonic antigen; AST, Aspartate Aminotransferase; PLT, Platelet.

the TGF-b-miR-34a-CCL22 axis might be related to the development of PVTT (28). Others have shown that liver fibrosis, severity of PVTT, and proteins induced by vitamin $\mathrm{K}$ absence or antagonist II (PIVKA-II) were independent prognostic factors for survival of HCC patients with PVTT (29). In contrast, a low serum concentration of des$\gamma$-carboxy prothrombin combined with curative resection of HCC with main portal vein PVTT was associated with improved 5-year survival (30). Multiple tumours, tumour rupture and macrovascular invasion have been identified as independent risk factors for recurrence and reduced survival in operated HCC patients with PVTT (31).
In the current study, incomplete tumor encapsulation, AST, and thickness of splenic hilum were independent risk factors of poor RFS. Additionally, independent risk factors for poor OS included $\alpha$-fetoprotein level, CEA, incomplete tumor encapsulation, and thickness of splenic hilum. Notably, the thickness of splenic hilum has reportedly been an indicator for splenomegaly, an independent risk factor for poor survival, and should be considered a novel prognostic factor for poor survival in patients with HCC and PVTT. Not surprisingly we found that RFS and OS in the nonSM group were significantly better than that of the SM group. Splenomegaly negatively impacted RFS and OS in 

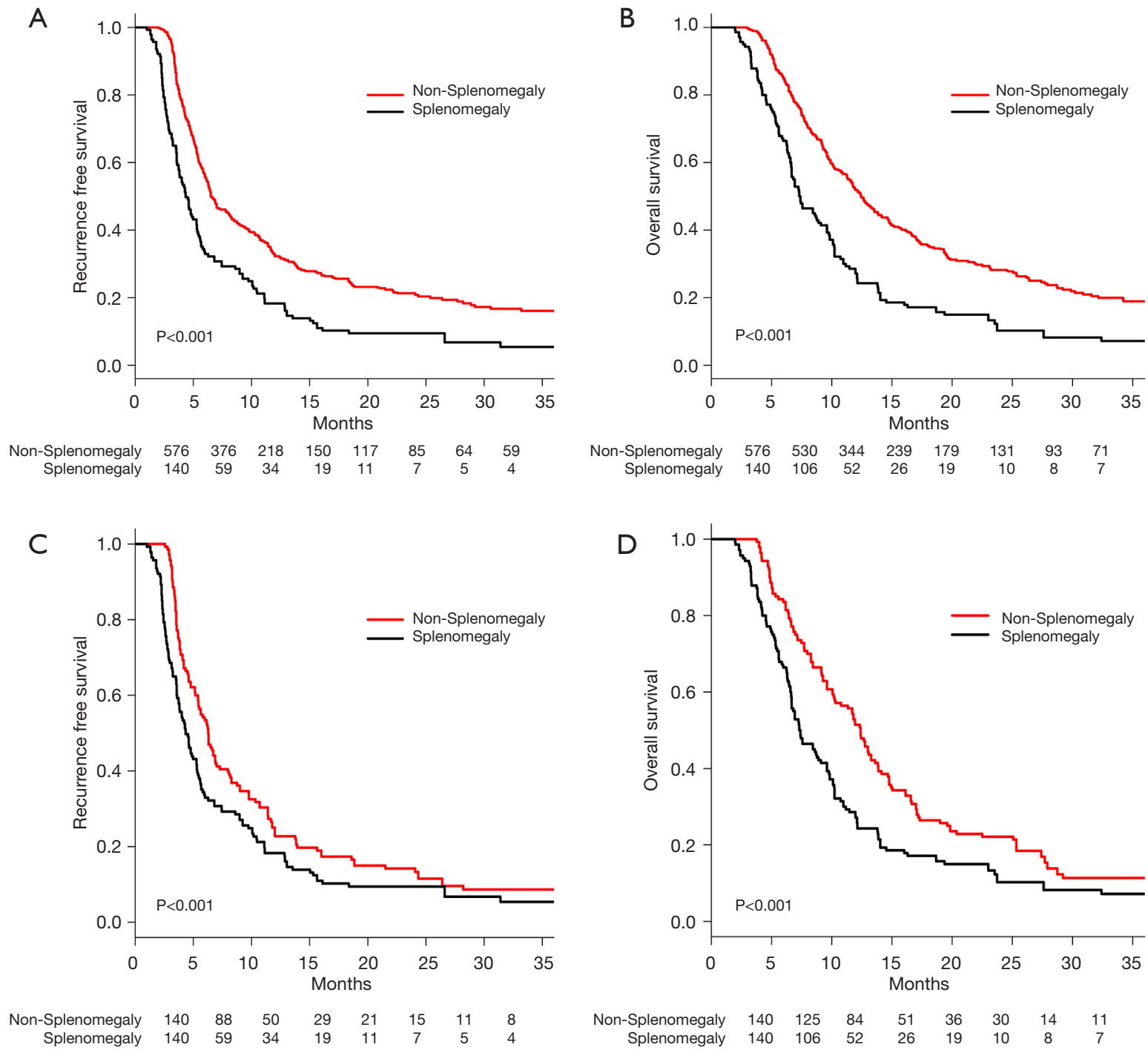

Figure 2 The survival analysis of patients with or without splenomegaly. (A) Kaplan-Meier analysis of RFS in patients with or without splenomegaly before PSM ( $\mathrm{P}<0.001)$. (B) Kaplan-Meier analysis of OS in patients with or without splenomegaly before PSM (P<0.001). (C) Kaplan-Meier analysis of RFS in patients with or without splenomegaly after PSM $(\mathrm{P}<0.001)$. (D) Kaplan-Meier analysis of OS in patients with or without splenomegaly after PSM $(\mathrm{P}<0.001)$. PSM, propensity score matching.

HCC patients with PVTT treated with LR. The reason appears to be directly related to hypersplenism $(32,33)$. HCC with PVTT is always complicated by decompensated liver function caused by liver cirrhosis. Decompensated liver function is accompanied by portal hypertension, splenomegaly with hypersplenism, all of which compromise the outcome of curative treatment $(34,35)$. Furthermore, hypersplenism decreases WBC and platelet counts, increasing risk of coagulopathy and infection. Ultimately it increases the risks of tumour recurrence and metastasis (36).

Due to the frequent potential postoperative complications associated with splenomegaly, splenectomy was performed prior to LR in these HCC patients. Reports have demonstrated that splenectomy has improved thrombocytopenia and leukopenia and decreased portal venous pressure $(15,37)$. Additionally, splenectomy may help to improve liver function, nutritional metabolism, and Child-Pugh scores which have expanded the indications for 

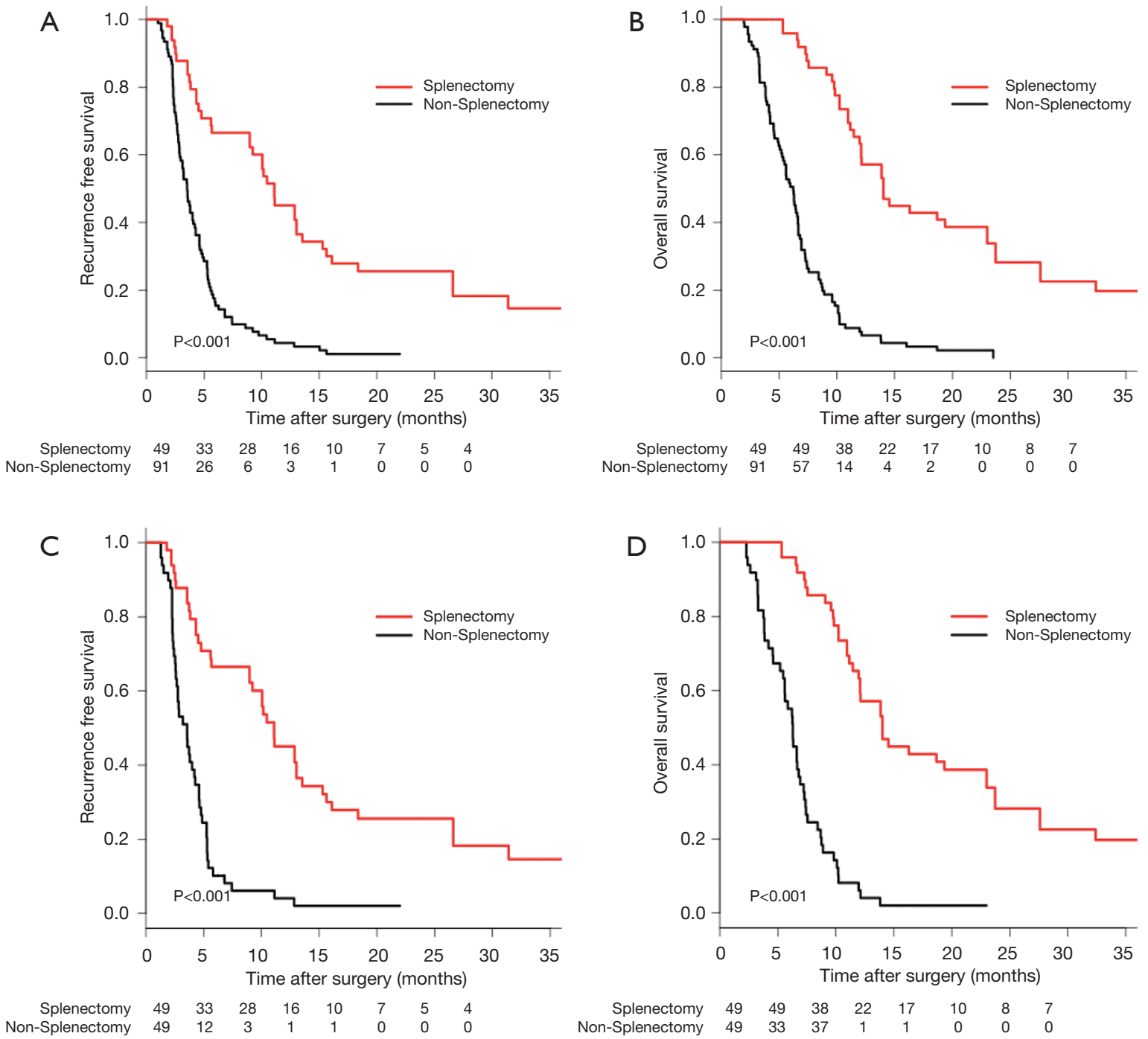

Figure 3 The survival analysis of patients with or without splenectomy. (A) Kaplan-Meier analysis of RFS in patients treated with or without splenectomy before PSM ( $\mathrm{P}<0.001)$. (B) Kaplan-Meier analysis of OS in patients treated with or without splenectomy before $\mathrm{PSM}$ (P<0.001). (C) Kaplan-Meier analysis of RFS in patients treated with or without splenectomy after PSM (P<0.001). (D) Kaplan-Meier analysis of OS in patients treated with or without splenectomy after PSM $(\mathrm{P}<0.001)$. PSM, propensity score matching.

LR and increased RFS (10,15,16,38-40). Some researchers advise synchronous hepatectomy and splenectomy in patients with HCC and a pathologic spleen (41). In this study, the long-term survival of HCC patients with PVTT in the SPT group was significantly better than the nonSPT group $(\mathrm{P}<0.001$ for OS and DFS). Studies suggest that splenectomy can restore lymphocyte function and induce tumour regression, perhaps due to increased number of natural killer (NK) cells, reduced transforming growth factor (TGF)- $\beta 1$ expression, and alteration of the immune response against cancer due to modulation of $\mathrm{CD} 4+$ and CD8+ T cells $(17,19,42,43)$. Splenectomy may even play a prophylactic role against HCC recurrence following LR (18). Taken together, these studies support our findings that splenectomy is beneficial for HCC patients with PVTT.

Our study has several limitations. First, it is a retrospective study with the usual attendant potential biases. Second, most patients enrolled in this study had a background of HBV infection. Whether the results of our study can be applied 
to patients with $\mathrm{HCV}$ or alcohol-related HCC remain to be determined.

In conclusion, HCC patients with PVTT but without splenomegaly had better long-term survival, but in patients with splenomegaly, splenectomy resulted in improved survival.

\section{Acknowledgments}

Funding: This work was supported by the grants of the National Natural Science Foundation of China [81702335].

\section{Footnote}

Reporting Checklist: The authors have completed the STROBE reporting checklist. Available at http://dx.doi. org/10.21037/atm-20-2229

Data Sharing Statement: Available at http://dx.doi. org/10.21037/atm-20-2229

Peer Review File: Available at http://dx.doi.org/10.21037/ atm-20-2229

Conflicts of Interest: All authors have completed the ICMJE uniform disclosure form (available at http://dx.doi. org/10.21037/atm-20-2229). The authors have no conflicts of interest to declare.

Ethical Statement: The authors are accountable for all aspects of the work in ensuring that questions related to the accuracy or integrity of any part of the work are appropriately investigated and resolved. The study was conducted in accordance with the Declaration of Helsinki (as revised in 2013). The study was approved by the Institutional Ethics Committees of the Eastern Hepatobiliary Surgery Hospital. (NO.: EHBHKY-2015-01-028) and informed consent was taken from all the patients.

Open Access Statement: This is an Open Access article distributed in accordance with the Creative Commons Attribution-NonCommercial-NoDerivs 4.0 International License (CC BY-NC-ND 4.0), which permits the noncommercial replication and distribution of the article with the strict proviso that no changes or edits are made and the original work is properly cited (including links to both the formal publication through the relevant DOI and the license).
See: https://creativecommons.org/licenses/by-nc-nd/4.0/.

\section{References}

1. Bray F, Ferlay J, Soerjomataram I, et al. Global cancer statistics 2018: GLOBOCAN estimates of incidence and mortality worldwide for 36 cancers in 185 countries. CA Cancer J Clin 2018;68:394-424.

2. Kokudo T, Hasegawa K, Matsuyama Y, et al. Survival benefit of liver resection for hepatocellular carcinoma associated with portal vein invasion. J Hepatol 2016;65:938-43.

3. Zhang XP, Wang K, Li N, et al. Survival benefit of hepatic resection versus transarterial chemoembolization for hepatocellular carcinoma with portal vein tumor thrombus: a systematic review and meta-analysis. BMC Cancer 2017;17:902.

4. Bruix J, Reig M, Sherman M. Evidence-Based Diagnosis, Staging, and Treatment of Patients With Hepatocellular Carcinoma. Gastroenterology 2016;150:835-53.

5. Marrero JA, Kulik LM, Sirlin C, et al. Diagnosis, Staging and Management of Hepatocellular Carcinoma: 2018 Practice Guidance by the American Association for the Study of Liver Diseases. Hepatology 2018;68:723-50.

6. Llovet JM, Ricci S, Mazzaferro V, et al. Sorafenib in advanced hepatocellular carcinoma. N Engl J Med 2008;359:378-90.

7. Cheng AL, Kang YK, Chen Z, et al. Efficacy and safety of sorafenib in patients in the Asia-Pacific region with advanced hepatocellular carcinoma: a phase III randomised, double-blind, placebo-controlled trial. Lancet Oncol 2009;10:25-34.

8. Zhang XP, Wang K, Guo WX, et al. Is Sorafenib an Optimal Treatment for Hepatocellular Carcinoma With Macrovascular Invasion or Metastatic Disease? Hepatology 2018;68:786.

9. Zhang XP, Gao YZ, Chen ZH, et al. An Eastern Hepatobiliary Surgery Hospital/Portal Vein Tumor Thrombus Scoring System as an Aid to Decision Making on Hepatectomy for Hepatocellular Carcinoma Patients With Portal Vein Tumor Thrombus: A Multicenter Study. Hepatology 2019;69:2076-90.

10. Sugawara Y, Yamamoto J, Shimada K, et al. Splenectomy in patients with hepatocellular carcinoma and hypersplenism. J Am Coll Surg 2000;190:446-50.

11. Poon RT, Fan ST, Lo CM, et al. Improving survival results after resection of hepatocellular carcinoma: a prospective study of 377 patients over 10 years. Ann Surg 
2001;234:63-70.

12. Dimick JB, Cowan JA Jr, Knol JA, et al. Hepatic resection in the United States: indications, outcomes, and hospital procedural volumes from a nationally representative database. Arch Surg 2003;138:185-91.

13. Looke DF, Runnegar NJ. Splenectomy and sepsis. Med J Aust 2012;196:587.

14. Bruix J, Sherman M, American Association for the Study of Liver D. Management of hepatocellular carcinoma: an update. Hepatology 2011;53:1020-2.

15. Amin MA, el-Gendy MM, Dawoud IE, et al. Partial splenic embolization versus splenectomy for the management of hypersplenism in cirrhotic patients. World J Surg 2009;33:1702-10.

16. Shimada M, Hashizume $M$, Shirabe K, et al. A new surgical strategy for cirrhotic patients with hepatocellular carcinoma and hypersplenism. Performing a hepatectomy after a laparoscopic splenectomy. Surg Endosc 2000;14:127-30.

17. Chen XP, Wu ZD, Huang ZY, et al. Use of hepatectomy and splenectomy to treat hepatocellular carcinoma with cirrhotic hypersplenism. Br J Surg 2005;92:334-9.

18. Zhang XY, Li C, Wen TF, et al. Synchronous splenectomy and hepatectomy for patients with hepatocellular carcinoma and hypersplenism: A case-control study. World J Gastroenterol 2015;21:2358-66.

19. Nomura Y, Kage M, Ogata T, et al. Influence of splenectomy in patients with liver cirrhosis and hypersplenism. Hepatol Res 2014;44:E100-9.

20. Takeishi K, Kawanaka H, Itoh S, et al. Impact of Splenic Volume and Splenectomy on Prognosis of Hepatocellular Carcinoma Within Milan Criteria After Curative Hepatectomy. World J Surg 2018;42:1120-8.

21. Shi J, Lai EC, Li N, et al. A new classification for hepatocellular carcinoma with portal vein tumor thrombus. J Hepatobiliary Pancreat Sci 2011;18:74-80.

22. Kong J, Shen S, Wang W. Synchronous hepatectomy and splenectomy vs. hepatectomy for selected patients with hepatocellular carcinoma and clinically significant portal hypertension: A systematic review and meta-analysis. J Surg Oncol 2019;119:964-73.

23. Kucybała I, Ciuk S, Tęczar J. Spleen enlargement assessment using computed tomography: which coefficient correlates the strongest with the real volume of the spleen? Abdom Radiol (NY) 2018;43:2455-61.

24. Giannini EG, Bucci L, Garuti F, et al. Patients with advanced hepatocellular carcinoma need a personalized management: A lesson from clinical practice. Hepatology
2018;67:1784-96.

25. Wang K, Guo WX, Chen MS, et al. Multimodality Treatment for Hepatocellular Carcinoma With Portal Vein Tumor Thrombus: A Large-Scale, Multicenter, Propensity Mathching Score Analysis. Medicine (Baltimore) 2016;95:e3015.

26. Peng ZW, Guo RP, Zhang YJ, et al. Hepatic resection versus transcatheter arterial chemoembolization for the treatment of hepatocellular carcinoma with portal vein tumor thrombus. Cancer 2012;118:4725-36.

27. Zhu K, Chen J, Lai L, et al. Hepatocellular carcinoma with portal vein tumor thrombus: treatment with transarterial chemoembolization combined with sorafenib--a retrospective controlled study. Radiology 2014;272:284-93.

28. Yang P, Li QJ, Feng Y, et al. TGF-beta-miR-34a-CCL22 signaling-induced Treg cell recruitment promotes venous metastases of $\mathrm{HBV}$-positive hepatocellular carcinoma. Cancer Cell 2012;22:291-303.

29. Gon H, Kido M, Tanaka M, et al. Growth velocity of the portal vein tumor thrombus accelerated by its progression, alpha-fetoprotein level, and liver fibrosis stage in patients with hepatocellular carcinoma. Surgery 2018;164:1014-22.

30. Matono R, Yoshiya S, Motomura T, et al. Factors linked to longterm survival of patients with hepatocellular carcinoma accompanied by tumour thrombus in the major portal vein after surgical resection. HPB (Oxford) 2012;14:247-53.

31. Xiao CZ, Wei W, Guo ZX, et al. A prognosis model for patients with hepatocellular carcinoma and portal vein tumor thrombus following hepatic resection. Oncol Lett 2015;10:2787-94.

32. Kawanaka H, Akahoshi T, Kinjo N, et al. Effect of laparoscopic splenectomy on portal haemodynamics in patients with liver cirrhosis and portal hypertension. Br J Surg 2014;101:1585-93.

33. Anegawa G, Kawanaka H, Uehara H, et al. Effect of laparoscopic splenectomy on portal hypertensive gastropathy in cirrhotic patients with portal hypertension. J Gastroenterol Hepatol 2009;24:1554-8.

34. Granito A, Bolondi L. Non-transplant therapies for patients with hepatocellular carcinoma and Child-PughTurcotte class B cirrhosis. Lancet Oncol 2017;18:e101-12.

35. Lv X, Yang F, Guo X, et al. Hypersplenism is correlated with increased risk of hepatocellular carcinoma in patients with post-hepatitis cirrhosis. Tumour Biol 2016;37:8889-900.

36. Li W, Shen SQ, Wu SM, et al. Simultaneous hepatectomy and splenectomy versus hepatectomy alone for 
hepatocellular carcinoma complicated by hypersplenism: a meta-analysis. Onco Targets Ther 2015;8:2129-37.

37. Alzen G, Basedow J, Luedemann M, et al. Partial splenic embolization as an alternative to splenectomy in hypersplenism--single center experience in 16 years. Klin Padiatr 2010;222:368-73.

38. Winslow ER, Brunt LM. Perioperative outcomes of laparoscopic versus open splenectomy: a meta-analysis with an emphasis on complications. Surgery 2003;134:64753; discussion 654-5.

39. Imura S, Shimada M, Utsunomiya T, et al. Impact of splenectomy in patients with liver cirrhosis: Results from 18 patients in a single center experience. Hepatol Res 2010;40:894-900.

40. Tomikawa M, Hashizume M, Akahoshi T, et al. Effects of splenectomy on liver volume and prognosis of cirrhosis in patients with esophageal varices. J Gastroenterol Hepatol 2002;17:77-80.

41. Zhang X, Li C, Wen T, et al. Synchronous splenectomy and hepatectomy for patients with small hepatocellular carcinoma and pathological spleen: neutrophil to lymphocyte ratio changes can predict the prognosis. Oncotarget 2017;8:46298-311.

42. Karakantza M, Mouzaki A, Theodoropoulou M, et al. Th1 and Th2 cytokines in a patient with Evans' syndrome and profound lymphopenia. Br J Haematol 2000;110:968-70.

43. Hashimoto N, Shimoda S, Kawanaka H, et al. Modulation of CD4(+) $\mathrm{T}$ cell responses following splenectomy in hepatitis $\mathrm{C}$ virus-related liver cirrhosis. Clin Exp Immunol 2011;165:243-50.
Cite this article as: Chai ZT, Zhang XP, Shao M, Ao JY, Chen ZH, Zhang F, Hu YR, Zhong CQ, Lin JH, Fang KP, Wu MC, Lau WY, Cheng SQ. Impact of splenomegaly and splenectomy on prognosis in hepatocellular carcinoma with portal vein tumor thrombus treated with hepatectomy. Ann Transl Med 2021;9(3):247. doi: 10.21037/atm-20-2229 
Table S1 the clinicopathological features of patients with or without splenomegaly after PSM

\begin{tabular}{|c|c|c|c|}
\hline Clinical variables & Splenomegaly $(n=140)$ & Non-Splenomegaly $(n=140)$ & $\mathrm{P}$ \\
\hline Age, year & $48.0(32.0-75.0)$ & $49.0(10.0-75.0)$ & 0.791 \\
\hline Sex & & & 1.000 \\
\hline Male & $126(90.0 \%)$ & $125(89.3 \%)$ & \\
\hline Female & $14(10.0 \%)$ & $15(10.7 \%)$ & \\
\hline Hepatitis B virus infection & & & 1.000 \\
\hline No & $33(23.6 \%)$ & $33(23.6 \%)$ & \\
\hline Yes & $107(76.4 \%)$ & $107(76.4 \%)$ & \\
\hline HBsAg & & & 0.675 \\
\hline No & $14(10 \%)$ & $11(7.9 \%)$ & \\
\hline Yes & $126(90 \%)$ & $129(92.1 \%)$ & \\
\hline Tumor diameter & $8.0(0.0-18.0)$ & $8.0(1.2-20.0)$ & 0.440 \\
\hline No\# of tumor & & & 1.000 \\
\hline Single & $122(87.1 \%)$ & $121(86.4 \%)$ & \\
\hline Multiple & $18(12.9 \%)$ & $19(13.6 \%)$ & \\
\hline PVTT & & & 0.615 \\
\hline I & $46(32.9 \%)$ & $51(36.4 \%)$ & \\
\hline II & $94(67.1 \%)$ & $89(63.6 \%)$ & \\
\hline Encapsulation & & & 0.057 \\
\hline No & $87(62.1 \%)$ & $87(62.1 \%)$ & \\
\hline Incomplete & $9(6.4 \%)$ & $20(14.3 \%)$ & \\
\hline Complete & $44(31.5 \%)$ & $33(23.6 \%)$ & \\
\hline Liver Cirrhosis & & & 0.870 \\
\hline No & $21(15.0 \%)$ & $23(16.4 \%)$ & \\
\hline Yes & $119(85.0 \%)$ & $117(83.6 \%)$ & \\
\hline Ascites & & & 1.000 \\
\hline No & $120(85.7 \%)$ & $119(85.0 \%)$ & \\
\hline Yes & $20(14.3 \%)$ & $21(15.0 \%)$ & \\
\hline Esophageal and gastric varices & & & 0.770 \\
\hline No & $109(77.9 \%)$ & $112(80.0 \%)$ & \\
\hline Yes & $31(22.1 \%)$ & $28(20.0 \%)$ & \\
\hline Child-Pugh & & & 0.684 \\
\hline A & $138(98.6 \%)$ & $136(97.1 \%)$ & \\
\hline B & $2(1.4 \%)$ & $4(2.9 \%)$ & \\
\hline Satellite lesions & & & 0.951 \\
\hline None & $11(7.9 \%)$ & $12(8.6 \%)$ & \\
\hline Same lobe & $117(83.6 \%)$ & $115(82.1 \%)$ & \\
\hline Different lobe & $12(8.6 \%)$ & $13(9.4 \%)$ & \\
\hline Thickness of splenic hilum & $5.0(4.1-15.0)$ & $4.0(4.0-4.0)$ & $<0.001$ \\
\hline TBIL & $15.0(5.3-32.0)$ & $13.0(4.0-34.0)$ & 0.054 \\
\hline DBIL & $6.0(2.1-16.0)$ & $5.0(1.0-13.0)$ & 0.139 \\
\hline ALB & $41.50(30.0-52.0)$ & $42.2(33.0-50.1)$ & 0.170 \\
\hline ALT & $47.0(11.0-262.0)$ & $39.0(14.0-303.0)$ & 0.291 \\
\hline PT & $12.5(0.0-112.0)$ & $11.9(0.0-15.5)$ & 0.179 \\
\hline GGT & $119.0(0.0-1052.0)$ & $121.5(23.0-810.0)$ & 0.324 \\
\hline ALP & $107.5(46.0-372.0)$ & $107.5(0.0-595.0)$ & 0.274 \\
\hline AFP & $1210.0(0.0-1210.0)$ & $940.1(0.6-1210.0)$ & 0.053 \\
\hline CA199 & $17.2(0.0-235.6)$ & $21.0(0.0-114.0)$ & 0.287 \\
\hline CEA & $2.0(0.0-12.0)$ & $2.3(0.0-14.9)$ & 0.594 \\
\hline AST & $47.0(14.9-390.0)$ & $51.0(15.7-359.0)$ & 0.602 \\
\hline PLT & $141.0(40.0-400.0)$ & $139.0(0.0-495.0)$ & 0.460 \\
\hline
\end{tabular}

Data were presented as $\mathrm{n}(\%)$ or medians with interquartile range (IQR). PSM, propensity score matching; HBsAg, Hepatitis $B$ surface antigen; PVTT, portal vein tumor thrombus; TBIL, Total Bilirubin; DBIL, Direct Bilirubin; ALB, Albumin; ALT, Alanine Aminotransferase; PT, Prothrombin time; GGT, $\gamma$-Glutamyltransferase; ALP, Alkaline phosphatase; AFP, $\alpha$-fetoprotein; CA199, Carbohydrate Atigen 19-9; CEA, Carcinoembryonic antigen; AST, Aspartate Aminotransferase; PLT, Platelet. 
Table S2 The clinicopathological features of patients with or without splenectomy after PSM

\begin{tabular}{|c|c|c|c|}
\hline Clinical variables & Splenectomy $(n=49)$ & Non-splenectomy $(n=49)$ & $P$ \\
\hline Age, year & $49.0(33.0-69.0)$ & $47.0(32.0-75.0)$ & 0.607 \\
\hline Sex & & & 1.000 \\
\hline Male & $46(93.9 \%)$ & 47 (95.9\%) & \\
\hline Female & $3(6.1 \%)$ & $2(4.1 \%)$ & \\
\hline Hepatitis B virus infection & & & 0.814 \\
\hline No & $11(22.4 \%)$ & $13(26.5 \%)$ & \\
\hline Yes & 38 (77.6\%) & $36(73.5 \%)$ & \\
\hline HBsAg & & & 0.912 \\
\hline No & $3(6.1 \%)$ & $3(6.1 \%)$ & 1.000 \\
\hline Yes & 46 (93.9\%) & $46(93.9 \%)$ & \\
\hline Tumor diameter & $8.0(1.2-15.0)$ & $7.3(0.0-14.4)$ & 0.855 \\
\hline No\# of tumor & & & 1.000 \\
\hline Single & $42(85.7 \%)$ & $42(86.5 \%)$ & \\
\hline Multiple & $7(14.3 \%)$ & $7(13.5 \%)$ & \\
\hline PVTT & & & 0.827 \\
\hline I & $16(32.7 \%)$ & $14(28.6 \%)$ & \\
\hline$\|$ & $33(67.3 \%)$ & $35(71.4 \%)$ & \\
\hline Encapsulation & & & 1.000 \\
\hline No & $31(63.3 \%)$ & $30(61.2 \%)$ & \\
\hline Incomplete & $3(6.1 \%)$ & $3(6.1 \%)$ & \\
\hline Complete & $15(30.6 \%)$ & $16(32.7 \%)$ & \\
\hline Liver Cirrhosis & & & 1.000 \\
\hline No & $7(14.3 \%)$ & $8(16.3 \%)$ & \\
\hline Yes & $42(85.7 \%)$ & $41(83.7 \%)$ & \\
\hline Ascites & & & 0.715 \\
\hline No & $44(89.8 \%)$ & $46(93.9 \%)$ & \\
\hline Yes & $5(10.2 \%)$ & $3(6.1 \%)$ & \\
\hline Esophageal and gastric varices & & & 1.000 \\
\hline No & $40(81.6 \%)$ & $40(81.6 \%)$ & \\
\hline Yes & $9(18.4 \%)$ & $9(18.4 \%)$ & \\
\hline Child-Pugh & & & 0.495 \\
\hline A & 47 (95.9\%) & 49 (100.0\%) & \\
\hline B & $2(4.1 \%)$ & $0(0.0 \%)$ & \\
\hline Satellite lesions & & & 1.000 \\
\hline None & $4(8.2 \%)$ & $4(8.2 \%)$ & \\
\hline Same lobe & $42(85,7 \%)$ & $41(83.6 \%)$ & \\
\hline Different lobe & $3(6.1 \%)$ & $4(8.2 \%)$ & \\
\hline Thickness of splenic hilum & $5.0(4.1-10.0)$ & $5(4.1-15.0)$ & 0.842 \\
\hline TBIL & $15.6(6.0-29.0)$ & $15.0(5.3-32.0)$ & 0.458 \\
\hline DBIL & $6.0(3.0-16.0)$ & $5.9(2.1-14.0)$ & 0.545 \\
\hline ALB & $41.0(30.0-52.0)$ & $30.0(30.0-49.0)$ & 0.858 \\
\hline ALT & $47.0(18.0-262.0)$ & $52.0(13.3-138.0)$ & 0.880 \\
\hline PT & $12.5(0.0-112.0)$ & $12.4(0.0-14.4)$ & 0.316 \\
\hline GGT & $122.0(36.0-1052.0)$ & $133.0(43.0-584.0)$ & 0.445 \\
\hline ALP & $107.0(60.0-372.0)$ & $112.0(62.0-255.0)$ & 0.418 \\
\hline AFP & $1000.0(1.0-1210.0)$ & $1210.0(0.0-1210.0)$ & 0.906 \\
\hline CA199 & $15.6(0.0-91.6)$ & $19.8(0.0-193.3)$ & 0.185 \\
\hline CEA & $2.0(0.0-7.2)$ & $2.0(0.0-5.0)$ & 0.700 \\
\hline AST & $41.0(17.1-263.0)$ & $42.0(17.1-184.0)$ & 0.740 \\
\hline PLT & $141.0(42.0-384.0)$ & $145.0(40.0-400.0)$ & 0.336 \\
\hline
\end{tabular}

Data were presented as $\mathrm{n}(\%)$ or medians with interquartile range (IQR). PSM, propensity score matching; HBsAg, Hepatitis $B$ surface antigen; PVTT, portal vein tumor thrombus; TBIL, Total Bilirubin; DBIL, Direct Bilirubin; ALB, Albumin; ALT, Alanine Aminotransferase; PT, Prothrombin time; GGT, $\gamma$-Glutamyltransferase; ALP, Alkaline phosphatase; AFP, $\alpha$-fetoprotein; CA199, Carbohydrate Atigen 19-9; CEA, Carcinoembryonic antigen; AST, Aspartate Aminotransferase; PLT, Platelet. 
Table S3 Comparison of RFS and OS rate among HCC patients with PVTT with or without splenomegaly before PSM

\begin{tabular}{|c|c|c|c|c|c|c|c|}
\hline Indexes & $\mathrm{n}$ & 1-year & 2-year & 3-year & Median survival time $(95 \% \mathrm{Cl})$ & Log-rank & $P$ value \\
\hline \multicolumn{8}{|l|}{ OS } \\
\hline Non-splenomegaly & 576 & $51.7(47.8-56.0)$ & $28.0(24.5-31.9)$ & $18.6(15.5-22.4)$ & $12.4(11.7-13.5)$ & 40.0 & $<0.001$ \\
\hline Splenomegaly & 140 & $25.7(19.4-34.1)$ & $10.2(6.1-17.2)$ & $7.2(3.7-13.9)$ & $7.4(6.7-9.6)$ & & \\
\hline \multicolumn{8}{|l|}{ RFS } \\
\hline Non-Splenomegaly & 576 & $32.3(28.6-36.4)$ & $21.1(17.9-24.8)$ & $16.1(13.1-19.7)$ & $6.5(6.3-7.8)$ & 35.1 & $<0.001$ \\
\hline Splenomegaly & 140 & $17.6(12.2-25.2)$ & $6.8(3.4-13.6)$ & $5.4(2.4-12.3)$ & $4.3(3.8-5.3)$ & & \\
\hline
\end{tabular}

RFS, recurrence-free survival; OS, overall survival; HCC, hepatocellular carcinoma; PVTT, portal vein tumor thrombus; PSM, propensity score matching.

Table S4 Comparison of RFS and OS rate among HCC patients with PVTT with or without splenectomy before PSM

\begin{tabular}{|c|c|c|c|c|c|c|c|}
\hline Indexes & $\mathrm{n}$ & 1-year & 2-year & 3-year & Median survival time $(95 \% \mathrm{Cl})$ & Log-rank & $P$ value \\
\hline \multicolumn{8}{|l|}{ OS } \\
\hline Non-splenomegaly & 91 & $6.6(3.0-14.2)$ & $0.0(0.0-0.0)$ & $0.0(0.0-0.0)$ & $6.2(5.4-6.7)$ & 66.4 & $<0.001$ \\
\hline Splenomegaly & 49 & $59.2(46.9-74.7)$ & $38.9(36.8-56.2)$ & $13.2(4.8-36.3)$ & $14.0(12.1-23.7)$ & & \\
\hline \multicolumn{8}{|l|}{ RFS } \\
\hline Non-Splenomegaly & 91 & $3.3(1.1-10.0)$ & $0.0(0.0-0.0)$ & $0.0(0.0-0.0)$ & $3.5(2.9-4.2)$ & 43.8 & $<0.001$ \\
\hline Splenomegaly & 49 & $42.9(30.8-59.7)$ & $18.3(9.3-36.0)$ & $14.6(6.5-32.8)$ & $11.1(9.0-15.3)$ & & \\
\hline
\end{tabular}

RFS, recurrence-free survival; OS, overall survival; HCC, hepatocellular carcinoma; PVTT, portal vein tumor thrombus; PSM, propensity score matching.

Table S5 Comparison of RFS and OS rate among HCC patients with PVTT with or without splenomegaly after PSM

\begin{tabular}{lccccccc}
\hline Indexes & $\mathrm{n}$ & 1-year & 2-year & 3-year & Median survival time $(95 \%$ Cl) & Log-rank & P value \\
\hline OS & & & & & & \\
$\quad$ Non-splenomegaly & 140 & $51.4(43.8-60.4)$ & $21.4(15.6-29.4)$ & $10.1(5.9-17.1)$ & $12.4(10.3-13.8)$ & 12.1 & $<0.001$ \\
$\quad$ Splenomegaly & 140 & $25.7(19.4-34.1)$ & $10.2(6.1-17.2)$ & $7.2(3.7-13.9)$ & $7.4(6.7-9.6)$ & & \\
RFS & & & & & & & \\
Non-splenomegaly & 140 & $22.8(16.7-31.0)$ & $18.3(8.6-20.6)$ & $7.2(3.6-14.2)$ & $6.3(5.4-7.3)$ & 7.6 & $<0.001$ \\
Splenomegaly & 140 & $17.6(12.2-25.2)$ & $6.8(3.4-13.6)$ & $5.4(2.4-12.3)$ & $4.3(3.8-5.3)$ & &
\end{tabular}

RFS, recurrence-free survival; OS, overall survival; HCC, hepatocellular carcinoma; PVTT, portal vein tumor thrombus; PSM, propensity score matching.

Table S6 Comparison of RFS and OS rate among HCC patients with PVTT with or without splenectomy after PSM

\begin{tabular}{lccccccc}
\hline Indexes & $\mathrm{n}$ & 1-year & 2-year & 3-year & Median survival time $(95 \% \mathrm{Cl})$ & Log-rank & $\mathrm{P}$ value \\
\hline OS & & & & & & \\
$\quad$ Non-splenectomy & 49 & $4.1(1.1-15.9)$ & $0.0(0.0-0.0)$ & $0.0(0.0-0.0)$ & $6.3(5.6-7.2)$ & 58.5 & $<0.001$ \\
$\quad$ Splenectomy & 49 & $59.2(46.9-74.7)$ & $38.9(36.8-56.2)$ & $13.2(4.8-36.3)$ & $14.0(12.1-23.7)$ & & \\
RFS & & & & & & & \\
$\quad$ Non-splenectomy & 49 & $2.0(0.3-14.2)$ & $0.0(0.0-0.0)$ & $0.0(0.0-0.0)$ & $3.6(2.7-4.6)$ & 36.6 & $<0.001$ \\
$\quad$ Splenectomy & 49 & $42.9(30.8-59.7)$ & $18.3(9.3-36.0)$ & $14.6(6.5-32.8)$ & $11.1(9.0-15.3)$ & & \\
\hline
\end{tabular}

RFS, recurrence-free survival; OS, overall survival; HCC, hepatocellular carcinoma; PVTT, portal vein tumor thrombus; PSM, propensity score matching. 